\title{
Climate change, ill health, and conflict
}

Lionel Jarvis ${ }^{a}$,

Hugh Montgomery ${ }^{b}$,

Neil Morisettic, Ian Gilmored

a Surgeon rear admiral, UK Ministry of Defence

b Director UCL Institute for Public Health and Performance, London

c Professor UK Ministry of Defence, London

d Professor, Royal Liverpool Hospital, London

For the full text article please see www.bmj.com/content/342/ bmj.d1819.ful
Contact:

Ruth van der Zypen-Millard

Political and Public

Affairs Officer

British Embassy

Thunstrasse 50

CH-3005 Bern

Tel. 0313597717
Are interrelated, so collaboration between medical and military professions is needed. Damage to the fabric of human society is bad for human health. It can occur for reasons other than war. A recent report by the International Institute for Strategic Studies (IISS) has highlighted that the effects of climate change will present a threat to collective security and global order in the first half of the 21st century. This will limit access to food, safe water, power, sanitation, and health services and drive mass migration and competition for remaining resources. Starvation, diarrhoea, and infectious diseases will become more common, and neonatal and adult mortality will rise, as a result of conflict. In accordance with this, in 2004 , seven of the 10 countries with the highest mortality rates in children under 5 were conflict or immediate post-conflict societies.

Climate change - which according to the ISS report is «directly attributable to the increasing emis- conflict. These could lead to failed states, which threaten global stability and security.» In this way, conflict and poor health feed upon one another.

Meanwhile, the world's population continues to expand: it is set to rise to 8.9 billions by 2050 , and the proportion of the population living in cities is increasing inexorably, from $13 \%$ in 1900 to an estimated $60 \%$ by 2030 . This urbanised population, increasingly focused in huge coastal megacities (in excess of 10 million), will become susceptible to the resource shortages of increasing demand and will place pressure on urban infrastructure. Damage to this fragile infrastructure by severe weather systems or rising sea levels will disrupt public health, and shortages of water, sanitation, heating, and food will combine to increase disease and ill health.

Like all good medicine, prevention is the key. The IISS report stresses the need for «sustained investment in infrastructure and new technologies» of

\section{«Climate change will increase the risks of resource shortages, mass migration, and civil conflict. These could lead to failed states, which threaten global stability and security.»}

sion of carbon dioxide and other greenhouse gases» will continue to drive extreme weather events and changes in water resources (through flood, drought, and rising sea levels), and it will adversely affect global food and energy production. Dennis Blair, director of National Intelligence for the United States, recently stated that, «Some recent climate science would indicate that the effects of climate change are accelerating.» In addition, the Pentagon's 2010 Quadrennial Defense Review to Congress stressed the potential for climate change to contribute to «poverty, environmental degradation, and the further weakening of fragile governments.» It continues with: «Climate change will contribute to food and water scarcity, will increase the spread of disease, and may spur or exacerbate mass migration», which in turn may increase the likelihood of instability and risk to national security.

Such statements resonate with those of a 2009 Lancet report, which made it clear that climate change is the biggest global health threat of the 21st century, with the greatest threat coming from effects on water and food security, human shelter and settlements, and resultant population migration. The IISS report concurs: «Climate change will increase the risks of resource shortages, mass migration, and civil which «a shift to renewable energy sources will be the most visible effect of efforts to mitigate emissions.»

We must adapt our cities and their infrastructure to cope with these challenges through combining engineering design and public health initiatives (for example, developing resilience in clean water and drainage systems, using human and food waste for energy generation, and building roads to act as flood pathways). As with prevention, effective adaptation will require an approach that encompasses the whole of society and international collaboration.

Such subjects will be discussed at the forthcoming open meeting "Climate change - how to secure our future wellbeing: a health and security perspective» at BMA House on 17 october 2011 (climatechange@bmj.com). Doctors, often seen as authoritative, trusted, and independent by their communities, must make their voices heard in calling for such action.

For more information on the meeting log on to http://resources.bmj.com/bmj/about-bmj/mediapartnerships/climate-change2014how-to-secureour-future-wellbeing-a-health-and-security-perspective or contact Geetha Balasubramaniam at geetha@ bmj.com 